Dept. of Public Hygiene,

Fac. of Veterinary Medicine, Al-Bath Univ., Syria.

\title{
IMPROVEMENT THE SENSORY PROPERTIES OF LOCAL YOGHURT BY ADDITION OF WHEY PROTEIN CONCENTRATE
}

(With 9 Tables)

\author{
By \\ N. AL-AMOR ; Y. HANAN and R. ATRA
}

(Received at 18/1/2011)

تحسين الخواص الحسية للبن الرائب المحلي باستخدام مركز بروتين المصل

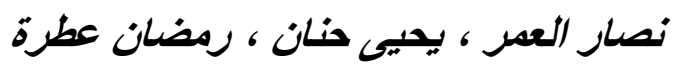

تبحث هذه الدر اسة في نوعية اللبن الرائب المحلي المثبت بإضافة مزيج من بودرة

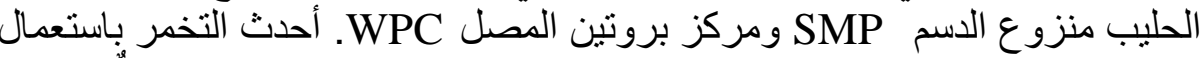

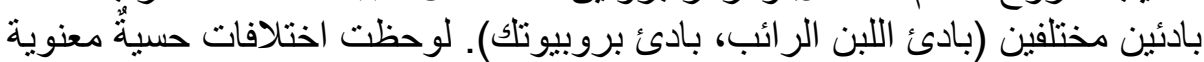

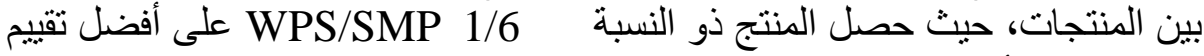

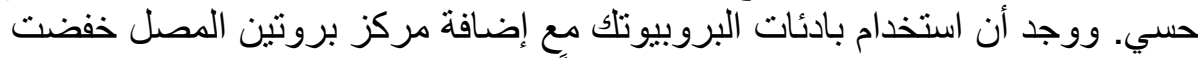

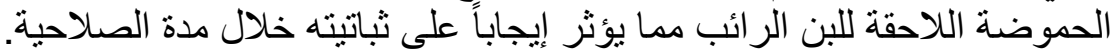

\section{SUMMARY}

The aim of the study was investigation of quality of settype yoghurt stabilized with addition of skim milk powder (SMP) and whey protein concentrate (WPC) blends. Fermentation was performed with two different starters (yoghurt culture, probiotic culture). Significant rheological differences have been noticed between the resulting yogurts,products with SMP/WPC ratio at 6/1 obtained the best sensory score.the use of probiotic starter and addition of WPC to yoghurt significantly decreased lactic acid concentration which positively influenced its stability during shelf life.

Key words: Milk, yoghurt, whey, protein. 


\section{INTRODUCTION

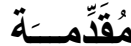

عرف الإنسان اللبن الرائب (اليوغورت) منذ 6000 سنة، ولعل كلمة "yoghurt" جاءت من كلمة "جوجورت" التركية و التي ظهرت في القرن الثامن .(Rasic et al., 1978)

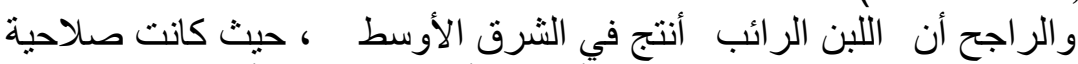

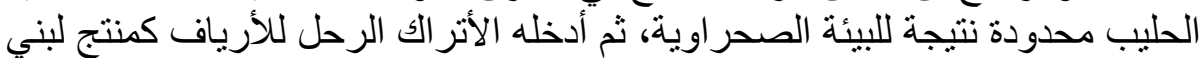

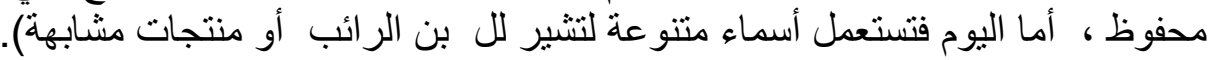

(Tamime et al., 1980; Tamime et al., 1985; Akin et al., 1994) يعرّف اليوغورت حسب دستور مفوضية الأغذية FAO/WHO بأنه " منتج

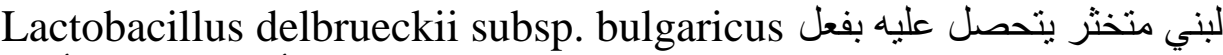

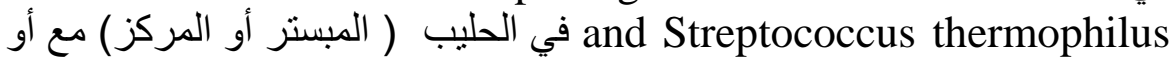

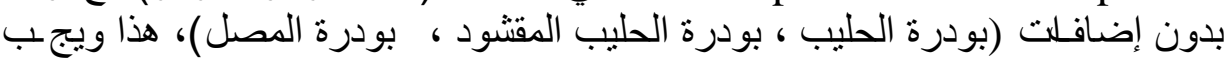

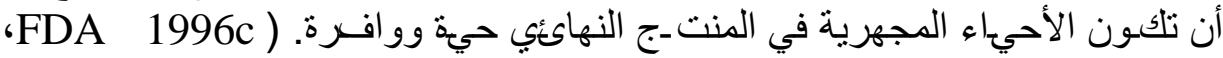
(Mareschi et al., 1989 عند تحضير خلطة اليو غورت غالباً ما تضاف مواد لبنية لزيادة المادة الصلبة

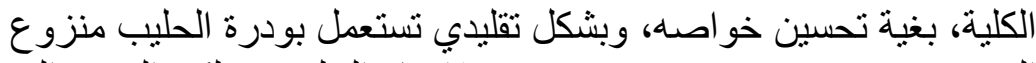

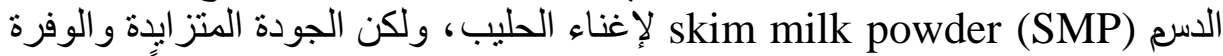

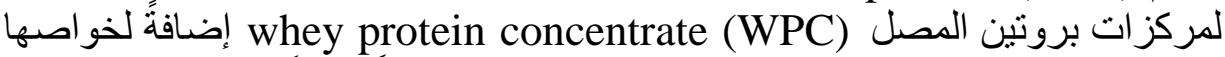
الوظيفية و الصحية جذبت المصنّعين إليها، وجعلت منها بديلاً شائعاً لبودرة الحليب منزوع الدسم في صناعة اللبن الر ائب. وقد تستعمل مو اد عير لبنية (نثاء، صمغ، جيلاتين، عديد السكريد). Tamime et al., 1994 ;Tamime et al., 1999 ;Sodini et al., 2005) .(Mistry et al., 1992

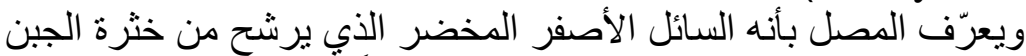

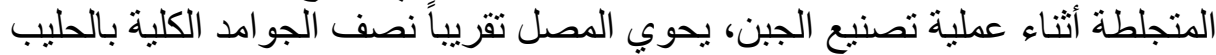

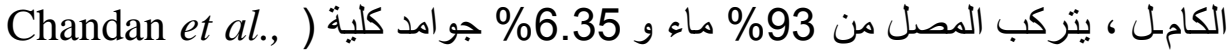
(Huffman et al., 1996 ; 1997

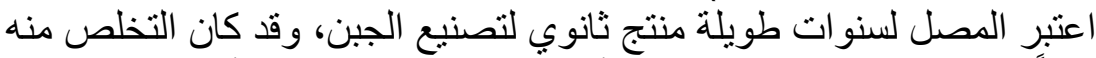

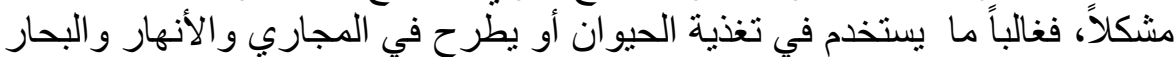
.(Smithers et al., 1996)

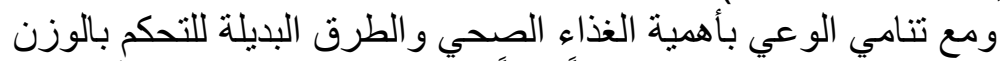

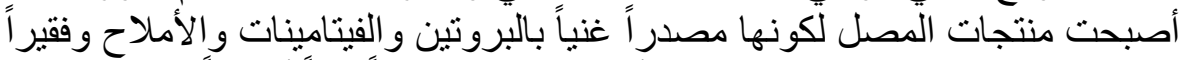

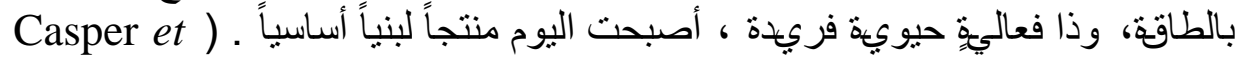
.(al., 1999 
ولصعوبة استعمال المصل بالثكل السائل ، لابد من خضو عه لعمليات التنقية

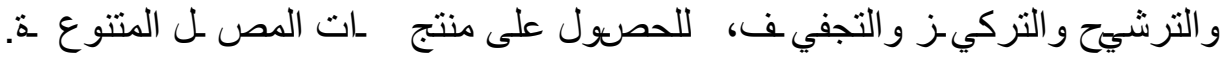
.(Smithers et al., 1996)

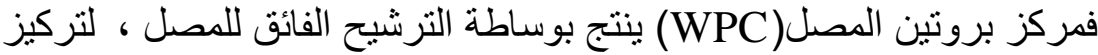

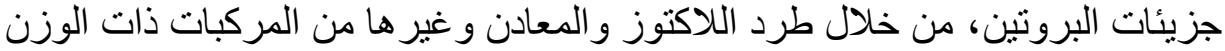

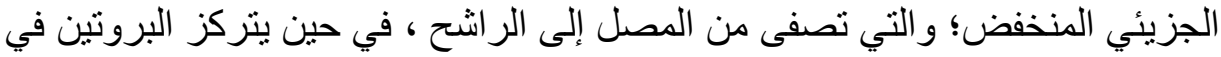

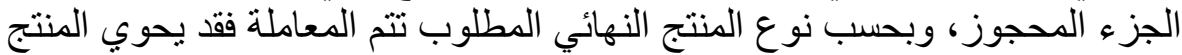
النهائي (34 إلى 80\%) بروتين، لذا توجد أنيو الن مختلفة من مركز ات بروتين المصل

WPC34 , WPC50 , WPC60 , WPC70 , WPC80 ويتركب بروتين المصل من: بيتالاكتو غلوبيولين 50 - 55\% و و ألفا لاكتو ألبو مين 20 \%

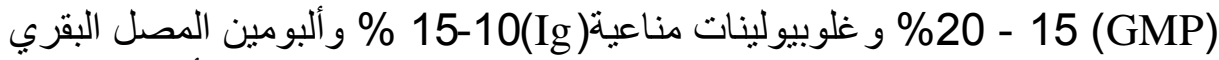

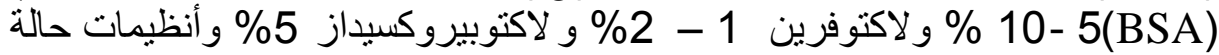

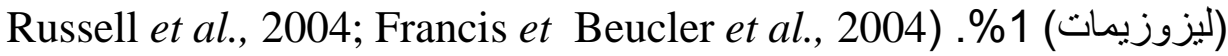
.(al., 2000;

إن التركيب الفريد لمركز بروتين المصل الذي يجمع خو اص تصنيعية (تهليم

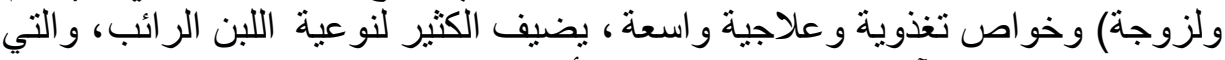
تدعمها من الجانب الآخر الفوائد المرجوة من أحياء البروبيوتلك (حافظـات الحياة)

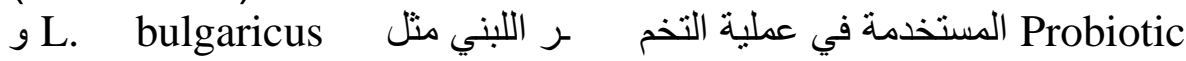
Bifidobacterium و L.acidophilus وSt.thermophilus أحياءالبروبيوتلك Probiotic حسب FAO/WHO بأنها أحباء مجهرية، عندما تستهلك

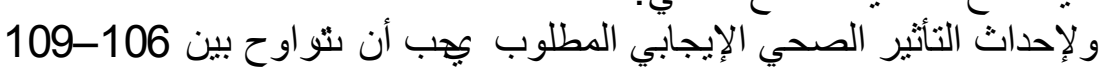

(Robinson et al., 2002) .CFU/g

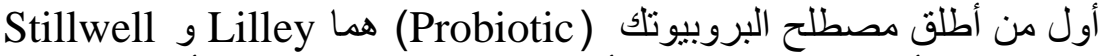
عام 1965 ويعني "لأجل الحياة". في حين أن العالم

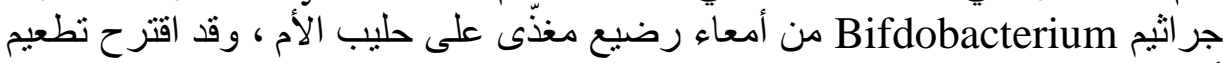

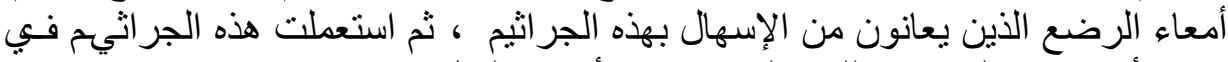

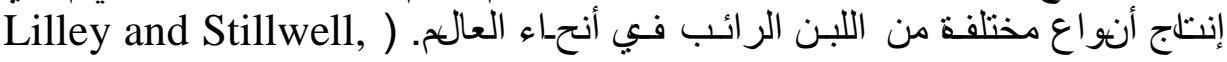
(1965

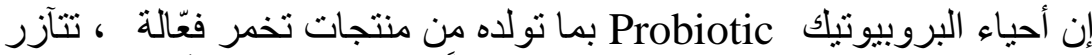

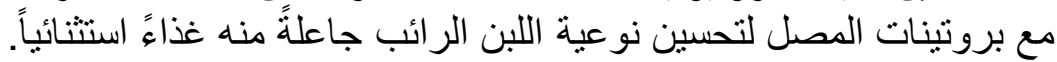

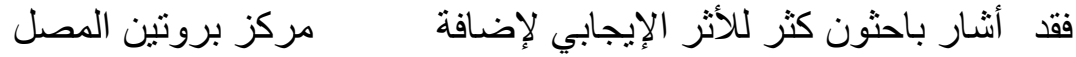

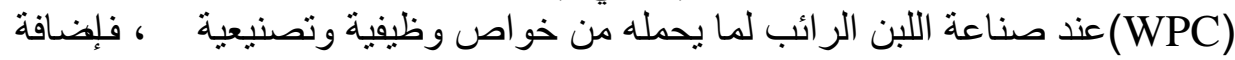

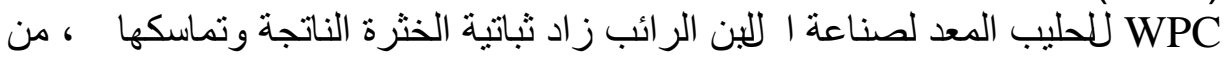

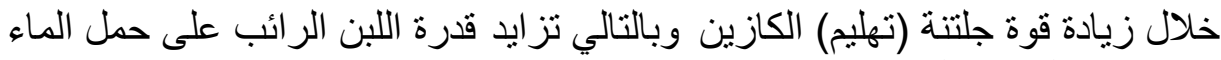

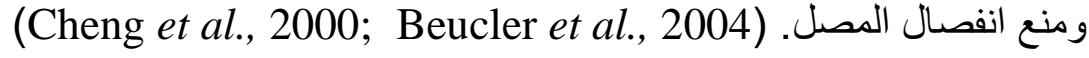




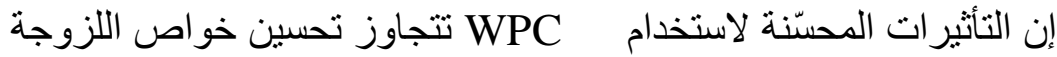

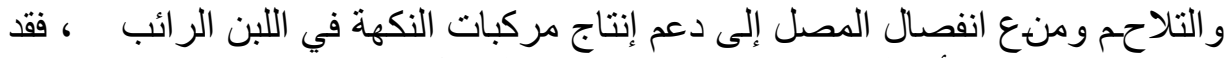

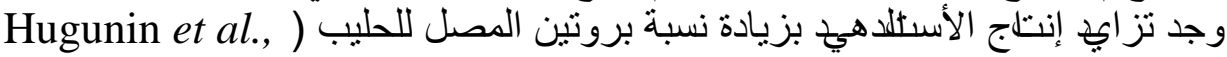

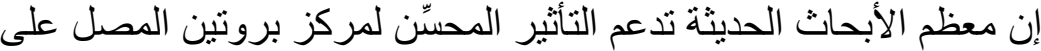

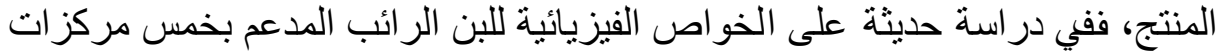

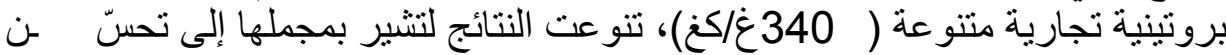

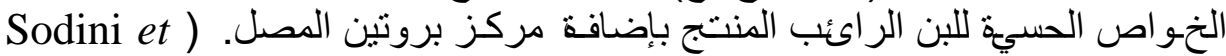
.(al., 2005

لم يقتصر التأثير المحسن لمركز بروتين المصل على الخو اص الحسية للبن التين

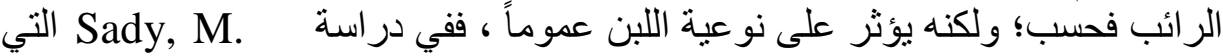

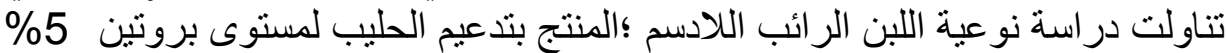

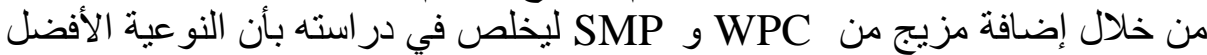

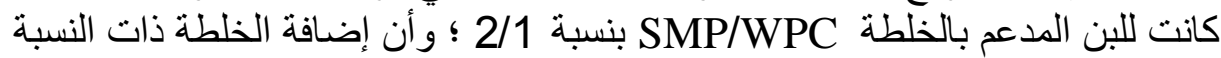

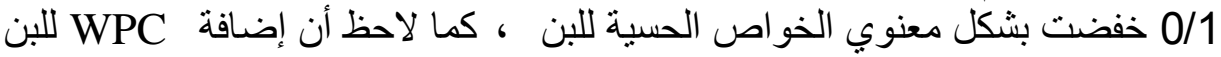

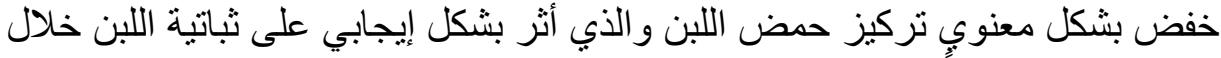
مدة تخزينه ، مشيراً إلى زيادة مو اد النكهة وارتفاع التعداد الكلي لجر الثيم البادئ (Sady et al., 2007)

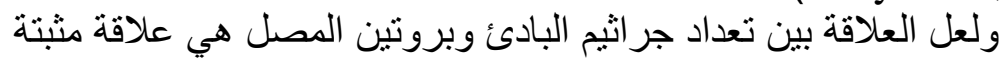

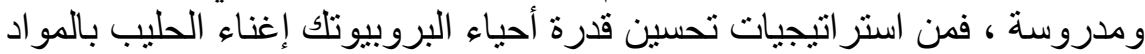

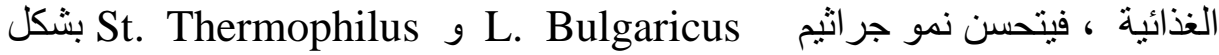

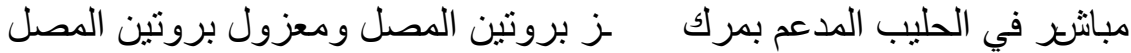

(Dave et al., 1996; Mccomas et al., 2003)

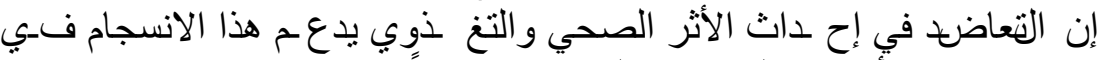

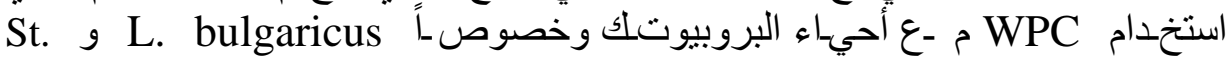
Thermophilus

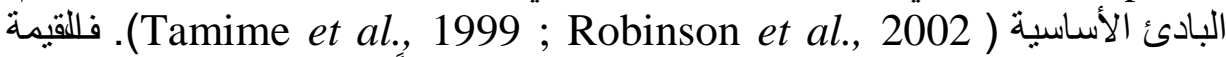

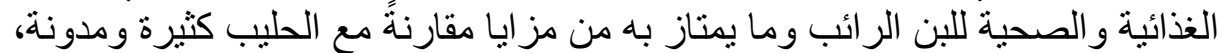

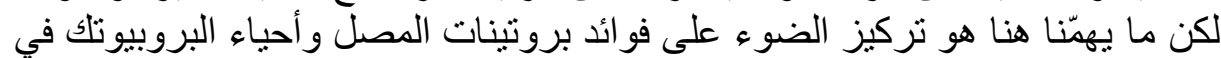

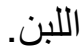

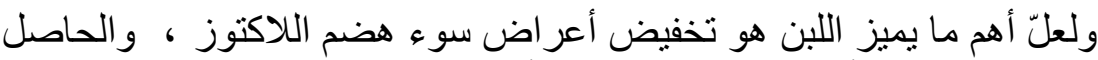

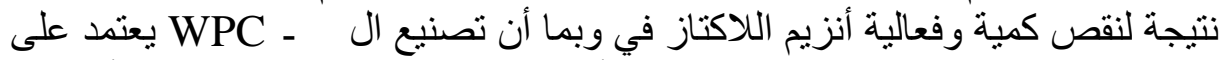

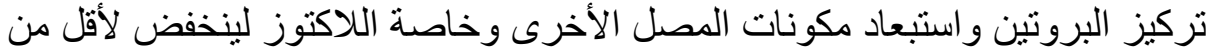

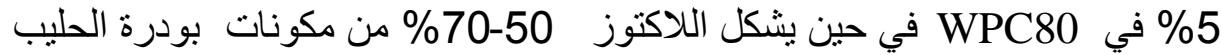

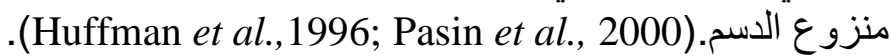
أما من جانب جر اثثم البادئ فقد أظهرت الأبحاث الكثيرة الدور الفعال لبادئ اللبن

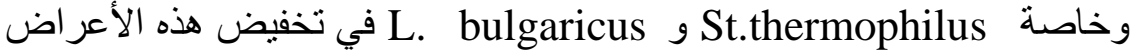


Mustapha et al., 1997; Guarner et al., 1998 ;Schorsch et al., 2001) (Kim.1983; Huis et al., 1994;

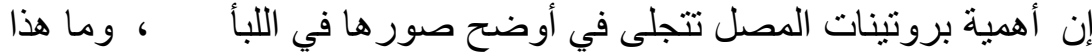

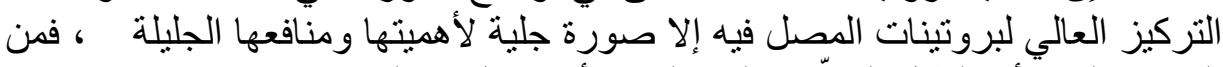

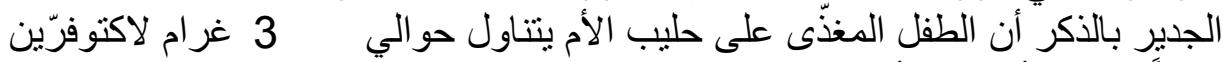

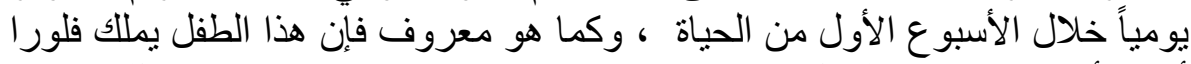

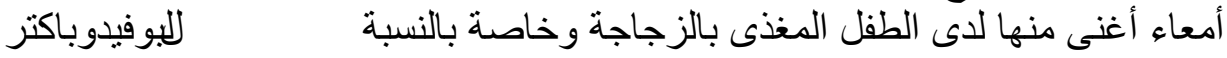

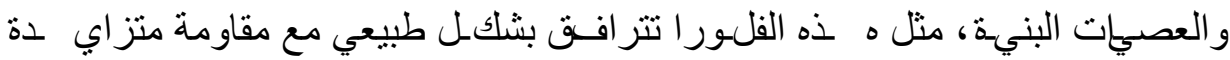

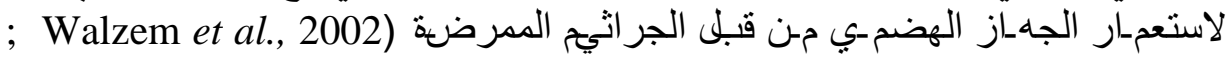
Reiter et al., 1985 Van Hooijdonk et al., 2000;

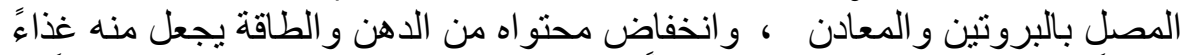

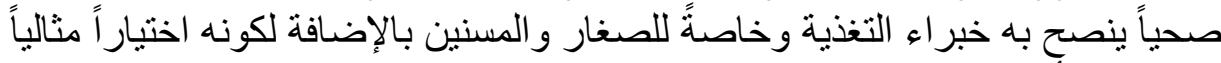

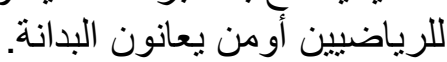

وقد تضافرت الأبحاث الحديثة التي تدعم القول بأن تناول الألبان المتخمرة

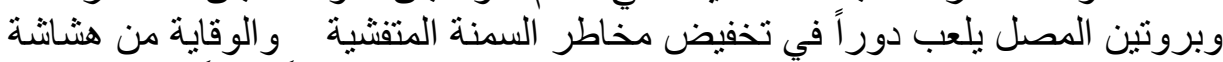

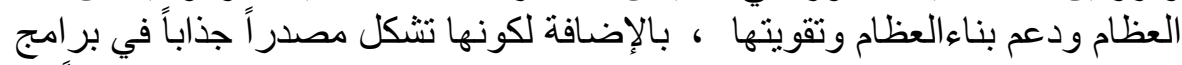

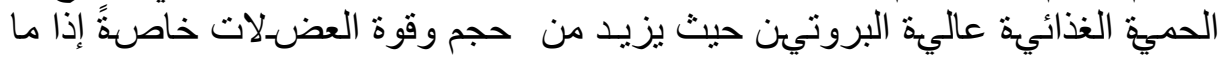
Yر افق ذلك مع برنامج تدريبٍ ثابت ( 2003 ( Toba et al., 2001 ; Burke et al., 2001; Aoe et al., 2001 ; 2002 Takada et al., 1997 Lands et al., 1999 ; Toba et al., 2000 ; .(Takada et al., 1996; Smithers et al., 1996;

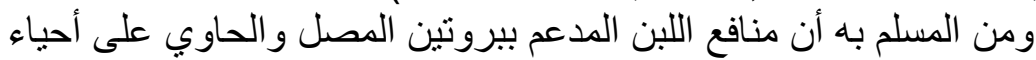

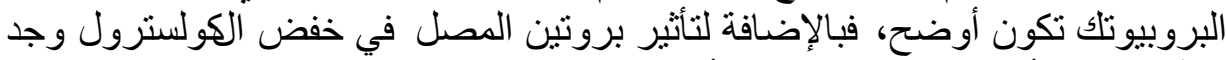

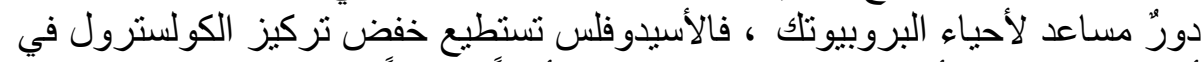

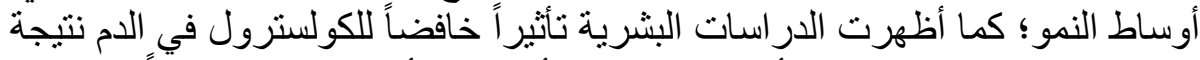

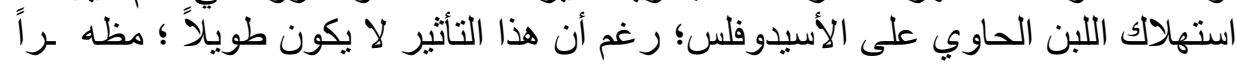

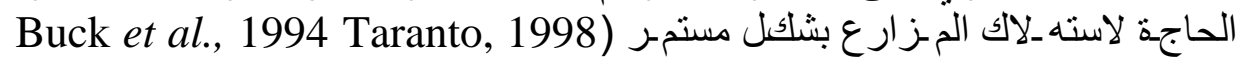
.) (; Gilliland et al., 1985; Walker et al., 1993; Ackley et al., 1983 إن هذا التآزر بين أحياء البروبيوتلك وبروتين المصل يبرز مجدئ مجداً في مقاومة

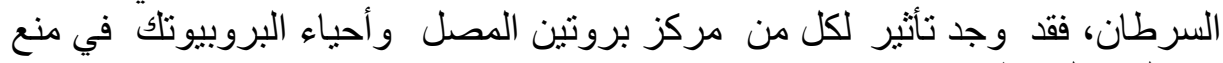

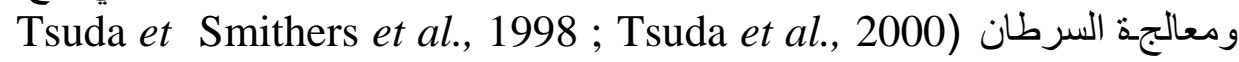
.(Weinberg et al., 1996; Sekine et al., 1997; al., 1998 إن مدار التأثثر النافع لتناول أحياء البروبيوتلك يبرز في التاع التحسينات المناعية

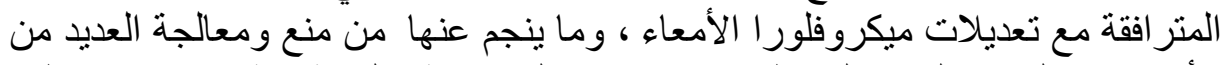

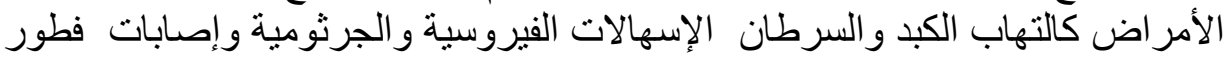
Yoo et al., 1998 ; Robinson et al., 2002 (الكانديدا والحساسية الإنة 


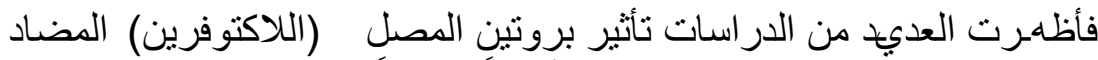

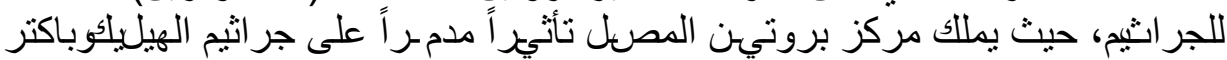

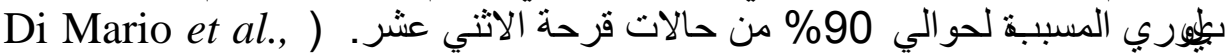
.(Early et al., 2001; 2003

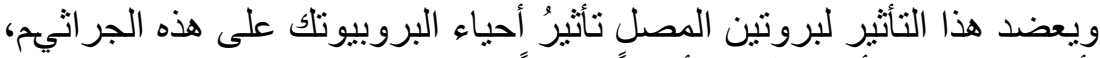

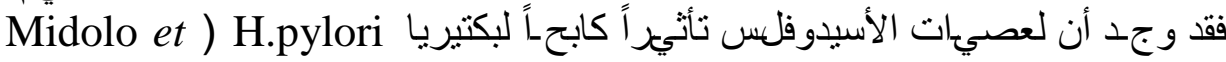
(Bhatia et al., 1989; al., 1995

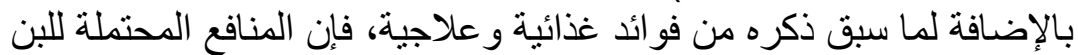

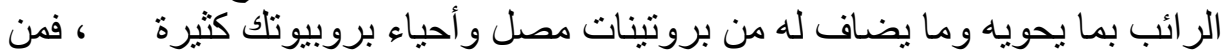

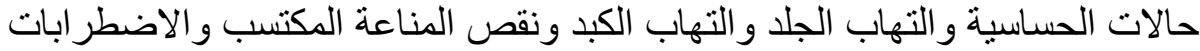

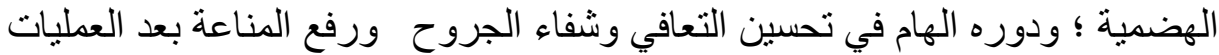

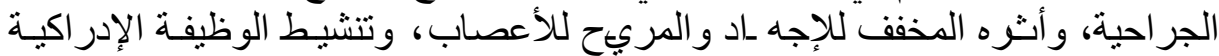

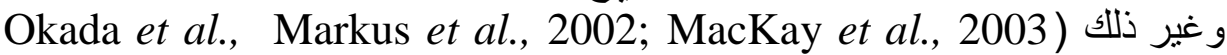
Zimecki et al., 2001; Markus et al., ، Vesovic et al., 2002 ; 2002

.(Graeff et al., 1996; 2000

كل ذلك يدفعنا للعمل الجاد و المبني على أسس علمية بغية إيجاد سبل تقود

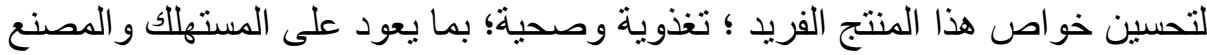
بالفائدة المرجوة.

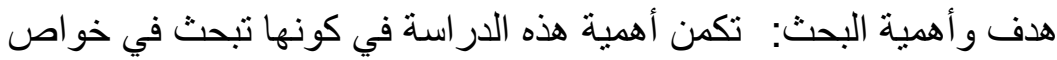

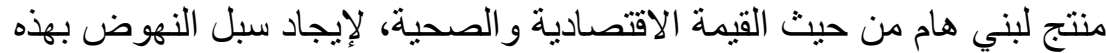

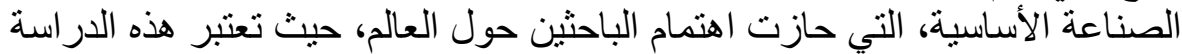

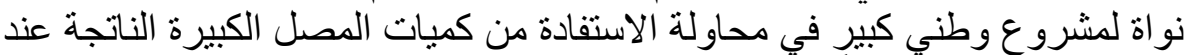

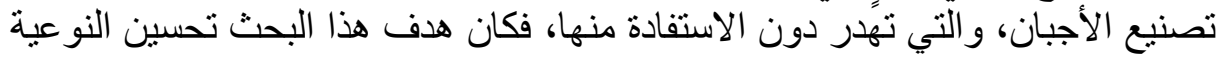

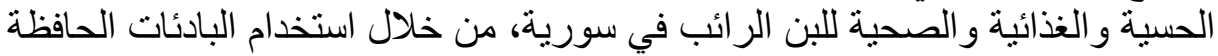
للحياة و إضافة مركز بروتين المصل.

\section{MATERIALS and METHODS المواد وطر ائق العمل}

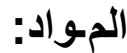

ـ الحليب المستخدم في تحضير المزارع الجرثومية هو حليب فرز، كما استخدمنا

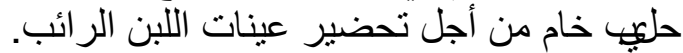

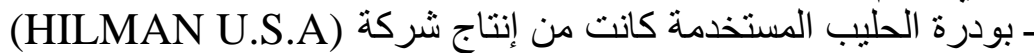

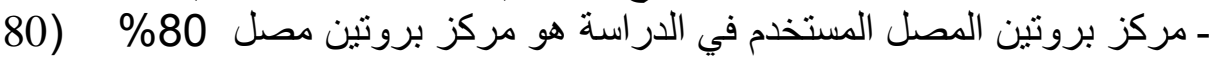

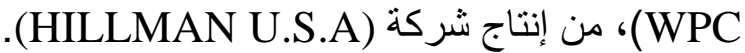

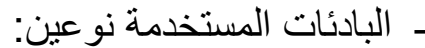




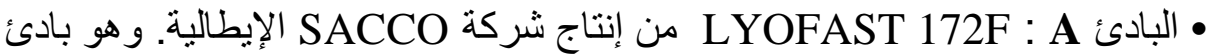

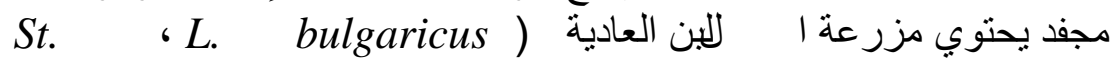

\section{.(thermophilus}

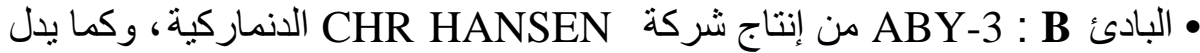

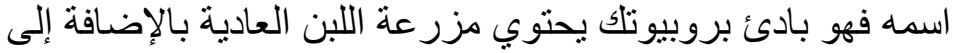
(Bifdiobacterium (BB-12) و L.Acidophilus(LA-5)

طرق القياس:

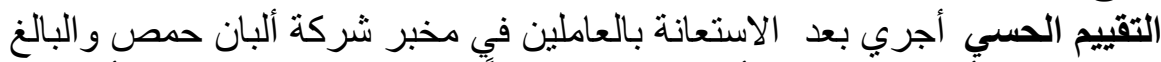

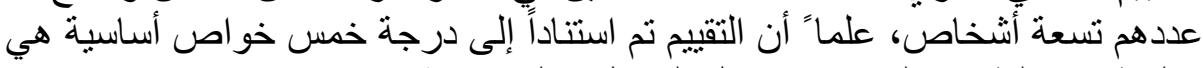

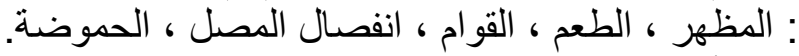

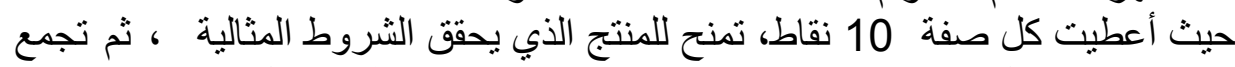

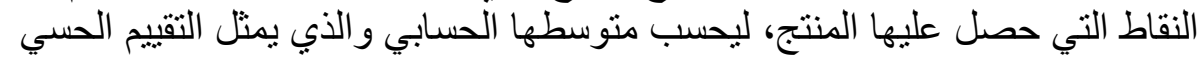

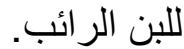

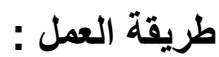

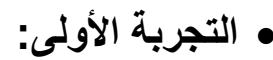

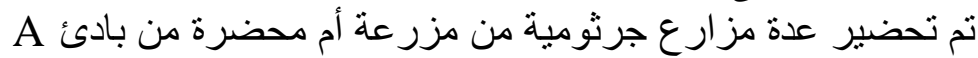

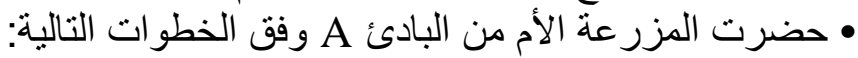

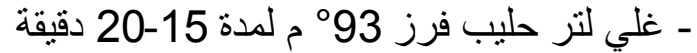

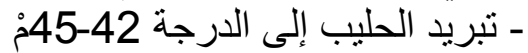
-

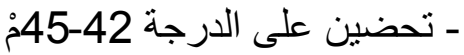

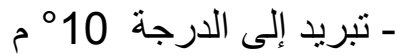

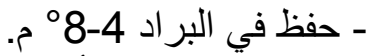

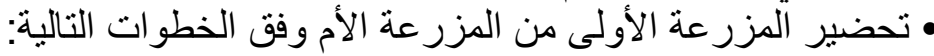

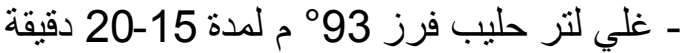

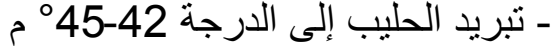

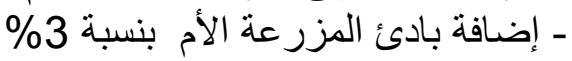

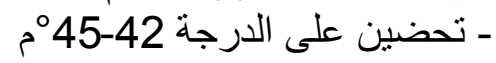

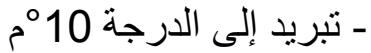

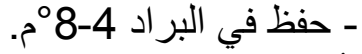

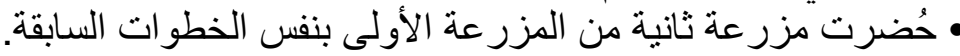

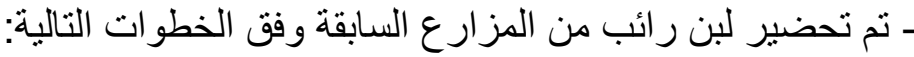

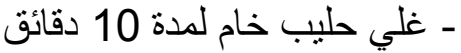
ـ تبريد الحليب إلى الدرجة 42-45 ماند -

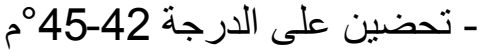

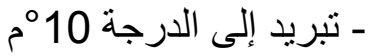




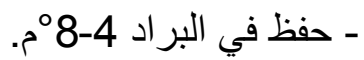
التجربة الثانية: البزان

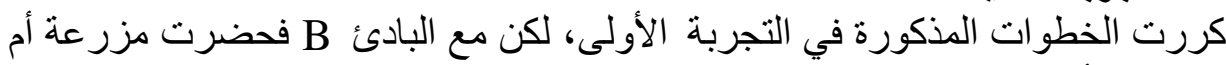

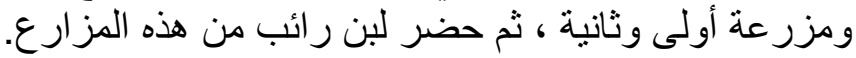
التجربة الثالثة:

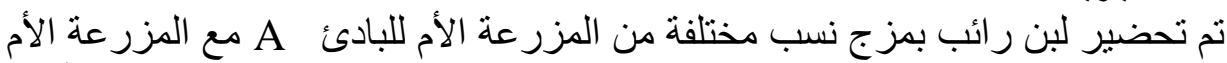

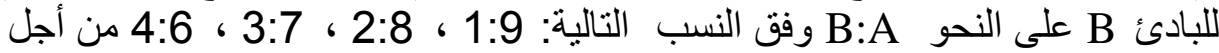
الوصول لأفضل خلطة بادئ.

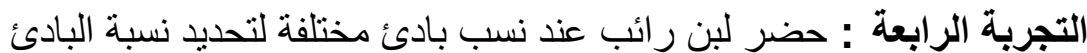

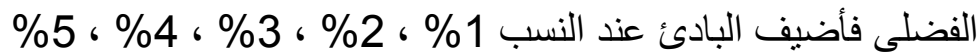

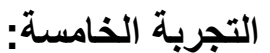

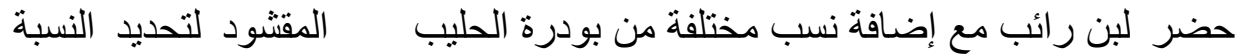

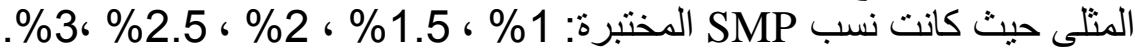

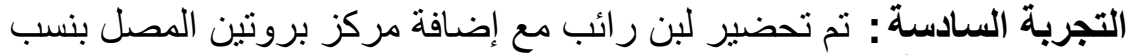

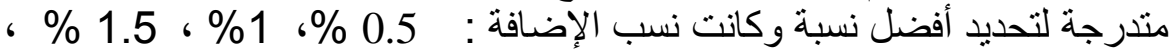
$\% 2.5$.\%2

مع ملاحظة أن إضافة بودرة الحليب ومركز البروتين يجب أن تكون قبل المعاملة الحرارية. التجربة السابعة: حضر لبن رائب باستخدام خلطة البادئ، مع إضافة بودرة حليب

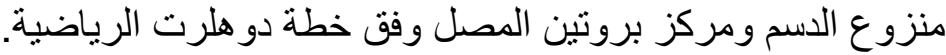

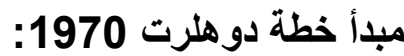

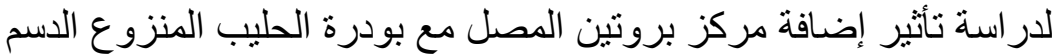

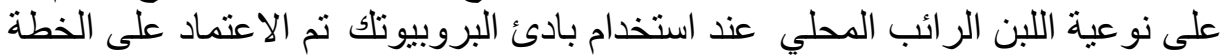

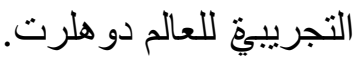

Dيث اعنمدت خطـة تجريبية حسب القالب المبين من قبل العالم

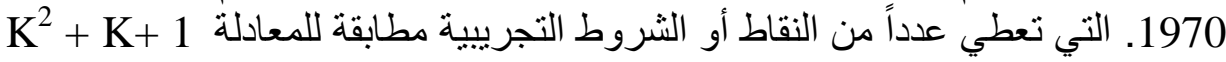

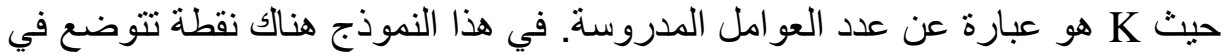

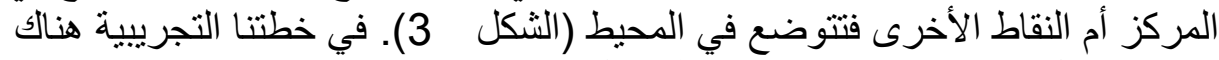

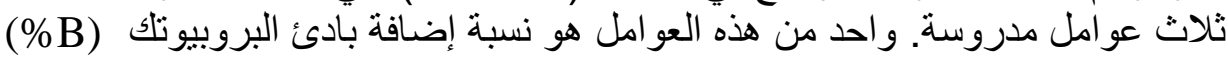

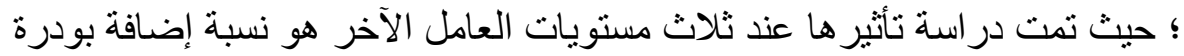

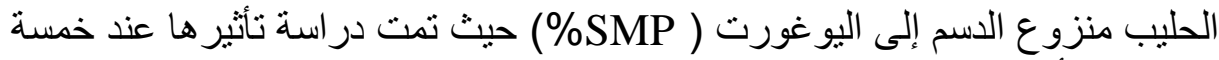

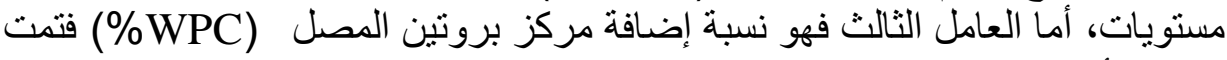
در اسة تأثير ها عند سبعة مستويات.

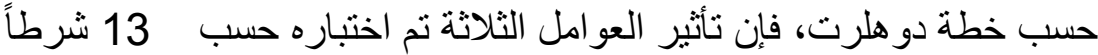
تجريبيا ، أما النقطة المركزية (

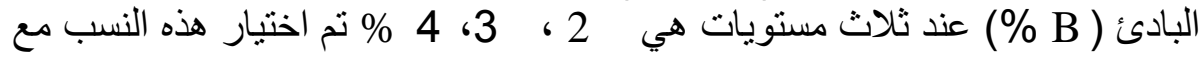


مر اعاة النسبة الفضلى لإضافة البادئ، حيث اخترنا قيمة أعلى و أخرى أدنى منها

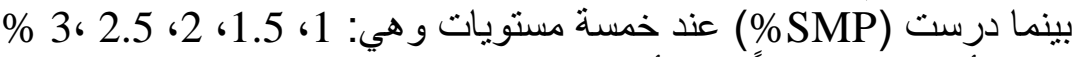

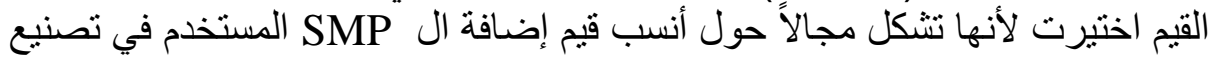
اللبن الرائب في الدر استة

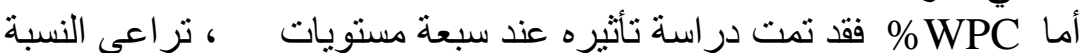

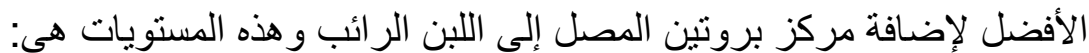

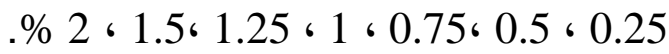

\begin{tabular}{|c|c|c|c|c|c|c|}
\hline \multirow{2}{*}{ الثيyyy|} & \multicolumn{3}{|c|}{} & \multicolumn{3}{c|}{} \\
\cline { 2 - 7 } & Starter\% & SMP & WPC & Starter\% & SMP\% & WPC\% \\
\hline C1 & 0,000 & 1,0 & 0,000 & 3 & 3 & 1 \\
\hline C2 & 0,000 & $+0,5$ & $+0,866$ & 3 & 2.5 & 2 \\
\hline C3 & $+0,816$ & $+0,5$ & $+0,289$ & 4 & 2.5 & 1.25 \\
\hline C4 & $-0,816$ & $+0,5$ & $-0,289$ & 2 & 2,5 & 0.75 \\
\hline C5 & 0,000 & $+0,5$ & $-0,866$ & 3 & 2.5 & 0.25 \\
\hline C6 & 0,000 & $-0,5$ & $+0,866$ & 3 & 1.5 & 2 \\
\hline C7 & $+0,816$ & $-0,5$ & 0,289 & 4 & 1.5 & 1.25 \\
\hline C8 & $-0,816$ & $-0,5$ & $-0,289$ & 2 & 1.5 & 0.75 \\
\hline C9 & 0,000 & $-0,5$ & $-0,866$ & 3 & 1.5 & 0.25 \\
\hline C10 & $-0,816$ & 0,0 & 0,577 & 2 & 2 & 1.5 \\
\hline C11 & 0,000 & 0,0 & 0,000 & 3 & 2 & 1 \\
\hline C12 & 0,816 & 0,0 & $-0,577$ & 4 & 2 & 0.5 \\
\hline C13 & 0,000 & $-1,0$ & 0,000 & 3 & 1 & 1 \\
\hline
\end{tabular}

\section{RESULTS}

النتائسـج

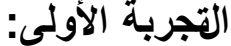

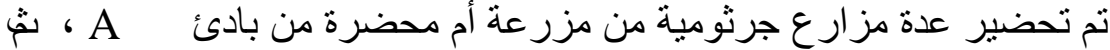

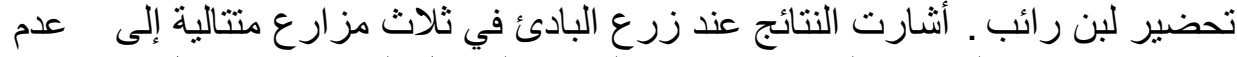

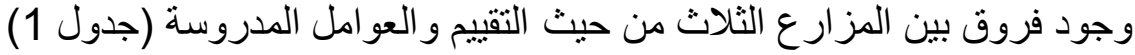

جدول 1: مزارع البادئ

\begin{tabular}{|c|c|c|c|}
\hline المزرعة الثانية & المزرعة الأولى & المزرعة الأم & المزرعة \\
\hline 2.45 & 2.40 & 2.30 & زمن لتحضين / ساعة \\
\hline
\end{tabular}


Assiut Vet. Med. J. Vol. 57 No. 129 April 2011

\begin{tabular}{|c|c|c|c|}
\hline 75 & 75 & 75 & $D$ D الحموضة المعايرة \\
\hline 10 & 10 & 10 & التقييم الحسي \\
\hline
\end{tabular}

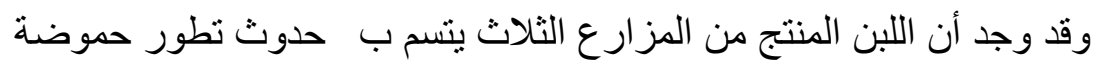

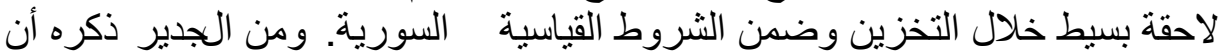

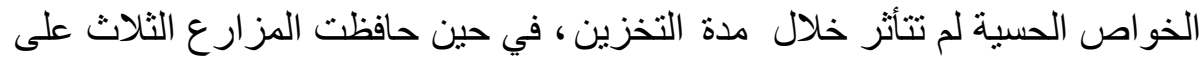

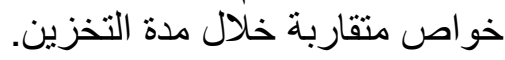
جدول 2: تغير حموضة اللبن المحضر مع الزمن

\begin{tabular}{|c|c|c|c|}
\hline \multicolumn{3}{|c|}{ D الحموضة المعايره D } & \multirow{2}{*}{ (يوم) } \\
\hline لبن مزر عة ثانية & لبن مزر عة أولى & لبن مزرعة أم & \\
\hline 80 & 79 & 79 & 1 \\
\hline 81 & 80 & 80 & 2 \\
\hline 82 & 81 & 80 & 3 \\
\hline 83 & 82 & 81 & 4 \\
\hline 83 & 82 & 81 & 5 \\
\hline
\end{tabular}

التجربة الثانية: تم تحضير عدة مزارع جرثثمية، ثثلبن رائب من البادئ B.

\begin{tabular}{|c|c|c|c|}
\hline المزر عة الثنانية & المزر عة الأولى & المزر عة الأم & لمز المزرعة \\
\hline 2.50 & 2.50 & 2.45 & زمن التحصين/ساعة \\
\hline 75 & 75 & 75 & الحموضة المعايرة D \\
\hline 8 & 7 & 6 & التقييم الحسي \\
\hline
\end{tabular}

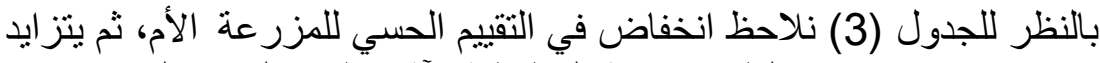
تدريجياً ، و هذا الانخفاض لإند (3) نلاحهور صفة المطاطية وآثار طعم حلو في المنتج. جدول 4: تغير حموضة اللبن المحضر من البادئ B مع الزمن

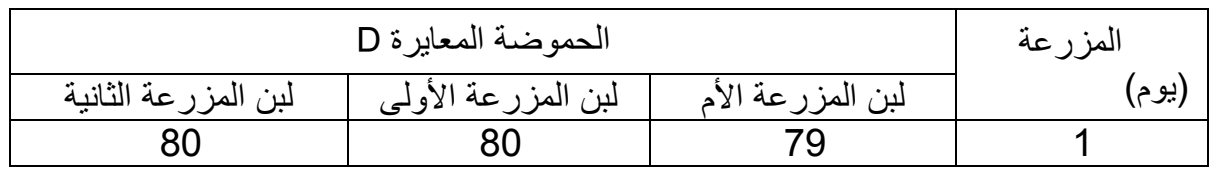


Assiut Vet. Med. J. Vol. 57 No. 129 April 2011

\begin{tabular}{|l|l|l|l|}
\hline 81 & 81 & 80 & 2 \\
\hline 82 & 82 & 82 & 3 \\
\hline 83 & 83 & 82 & 4 \\
\hline 83 & 83 & 82 & 5 \\
\hline
\end{tabular}

من خلال الجدول (4) نلاحظ تطور ضعيف للحموضة اللاحقة أثناء التخزين،

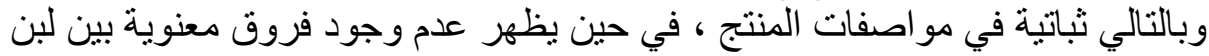
المزارع الثناث.

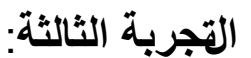

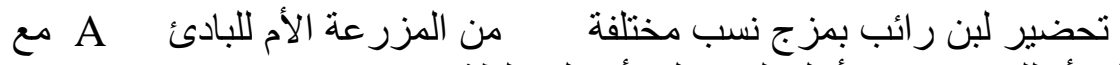

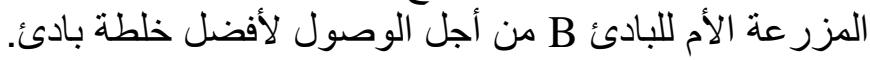

\begin{tabular}{|c|c|c|c|c|}
\hline التقييم الحسي & لبن مزر عة & لبن مزر أولى & لبن مزر عة أم & المزرعة \\
\hline 10 & 80 & 79 & 79 & $1: 9$ \\
\hline 10 & 80 & 80 & 79 & $2: 8$ \\
\hline 8 & 81 & 80 & 80 & $3: 7$ \\
\hline 7 & 81 & 80 & 80 & $4: 6$ \\
\hline
\end{tabular}

ملاحظة: هذه القياسات و القيم أخذت على لبن بعمر يوم. كما يظهر الجدول (5) فالنسبة المنلى لمزج الفئل البادئين B:A كانت 2:8 وذلك تبعاً للتقييم

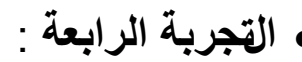
تخضيي لبن ر ائب عند نسب بادئ مختلفة لتحديد نسبة البادئ الفضلى . جدول 6: تطور الحموضة خلال التحضين باختلاف نسبة البادئ

\begin{tabular}{|c|c|c|c|c|c|c|}
\hline \multicolumn{6}{|c|}{ الحموضة المعايرة D } & \multirow{2}{*}{ لنسبة ز زمن دقيقة } \\
\hline 180 & 150 & 120 & 90 & 60 & 30 & \\
\hline 62 & 57 & 52 & 40 & 29 & 22 & 1 \\
\hline 76 & 71 & 61 & 49 & 37 & 25 & 2 \\
\hline 80 & 75 & 63 & 52 & 39 & 27 & 3 \\
\hline 82 & 76 & 65 & 53 & 40 & 29 & 4 \\
\hline 86 & 80 & 69 & 59 & 48 & 32 & 5 \\
\hline
\end{tabular}

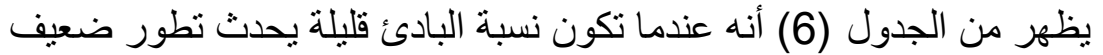
للحموضة مع ضعف (هشاشة) في الخثرة الناتجة، كانت أفضل النتائج مع النسبة 3. 
• التجربة الخامسة:

تمضيي لبن رائب مع نسب مختلفة من بودرة الحليب المقتود لتحديد النسبة الأمثل.

جدول 7: تغير الحموضة باختلاف نسبة SMP

\begin{tabular}{|c|c|c|c|c|c|c|}
\hline 3 & 2.5 & 2 & 1.5 & 1 & 0 & $\begin{array}{l}\text { SMP\% } \\
\text { SMوم }\end{array}$ \\
\hline 82 & 81 & 80 & 80 & 79 & 79 & 1 \\
\hline 83 & 82 & 81 & 81 & 80 & 80 & 2 \\
\hline 84 & 83 & 82 & 82 & 81 & 80 & 3 \\
\hline 85 & 83 & 82 & 82 & 81 & 81 & 4 \\
\hline 86 & 84 & 82 & 82 & 81 & 81 & 5 \\
\hline 7 & 8 & 10 & 9 & 8 & 8 & تقييم حسم \\
\hline
\end{tabular}

من خلال الجدول (7) نلاحظ:

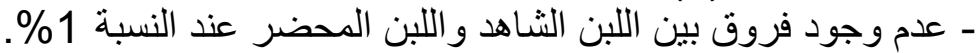

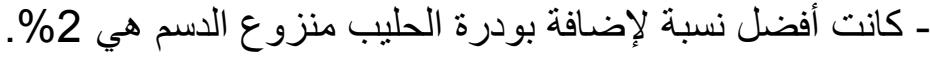
التجربة السادسة:

تم تحضير لبن رائب مع إضافة مركز بروتين المصل بنسب متدرجة لتحديد أفضل.

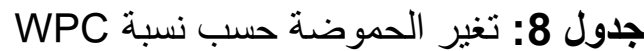

\begin{tabular}{|c|c|c|c|c|c|}
\hline 1.5 & 1 & 0.5 & 0.25 & 0 & WPC \% \\
\hline 76 & 77 & 77 & 79 & 79 & 1 \\
\hline 77 & 78 & 78 & 80 & 80 & 2 \\
\hline 79 & 79 & 79 & 80 & 80 & 3 \\
\hline 79 & 80 & 80 & 81 & 81 & 4 \\
\hline 79 & 80 & 80 & 81 & 81 & 5 \\
\hline 7 & 10 & 9 & 8 & 8 & التقييم الحسي \\
\hline
\end{tabular}

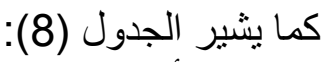
、

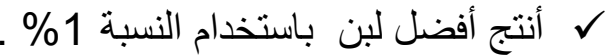

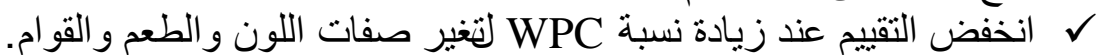
ل

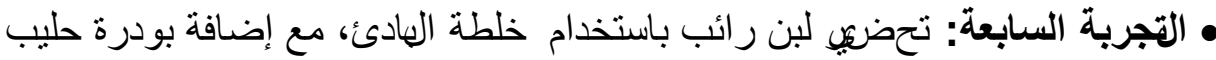

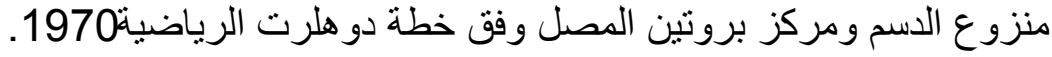




\begin{tabular}{|c|c|c|c|c|}
\hline الثرط & البادئ & SMP & WPC & التقييم الحسي \\
\hline $\mathrm{C} 1$ & 30 & 30 & 10 & 4 \\
\hline $\mathrm{C} 2$ & 30 & 25 & 20 & 3 \\
\hline $\mathrm{C} 3$ & 40 & 25 & 12.5 & 5 \\
\hline $\mathrm{C} 4$ & 20 & 25 & 7.5 & 8 \\
\hline $\mathrm{C} 5$ & 30 & 25 & 2.5 & 9 \\
\hline C6 & 30 & 15 & 20 & 4 \\
\hline $\mathrm{C7}$ & 40 & 15 & 12.5 & 6 \\
\hline $\mathrm{C} 8$ & 20 & 15 & 7.5 & 6 \\
\hline C9 & 30 & 15 & 2.5 & 10 \\
\hline $\mathrm{C} 10$ & 20 & 20 & 15 & 4 \\
\hline $\mathrm{C} 11$ & 30 & 20 & 10 & 6 \\
\hline $\mathrm{C} 12$ & 40 & 20 & 5 & 9 \\
\hline $\mathrm{C} 13$ & 30 & 10 & 10 & 7 \\
\hline
\end{tabular}

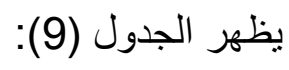

أن أفضل شرط في التجربة هول c9 ، في حين كان الثرطين C12 ، C5 جيدين. كما

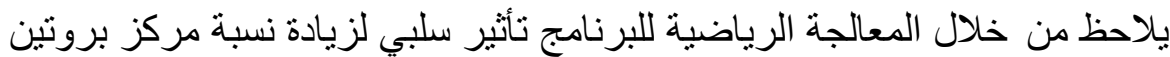

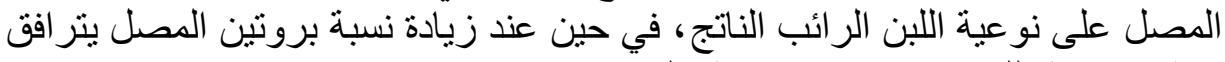
تحسّن نوعية اللبن مع زيادة في نسبة البادئ.

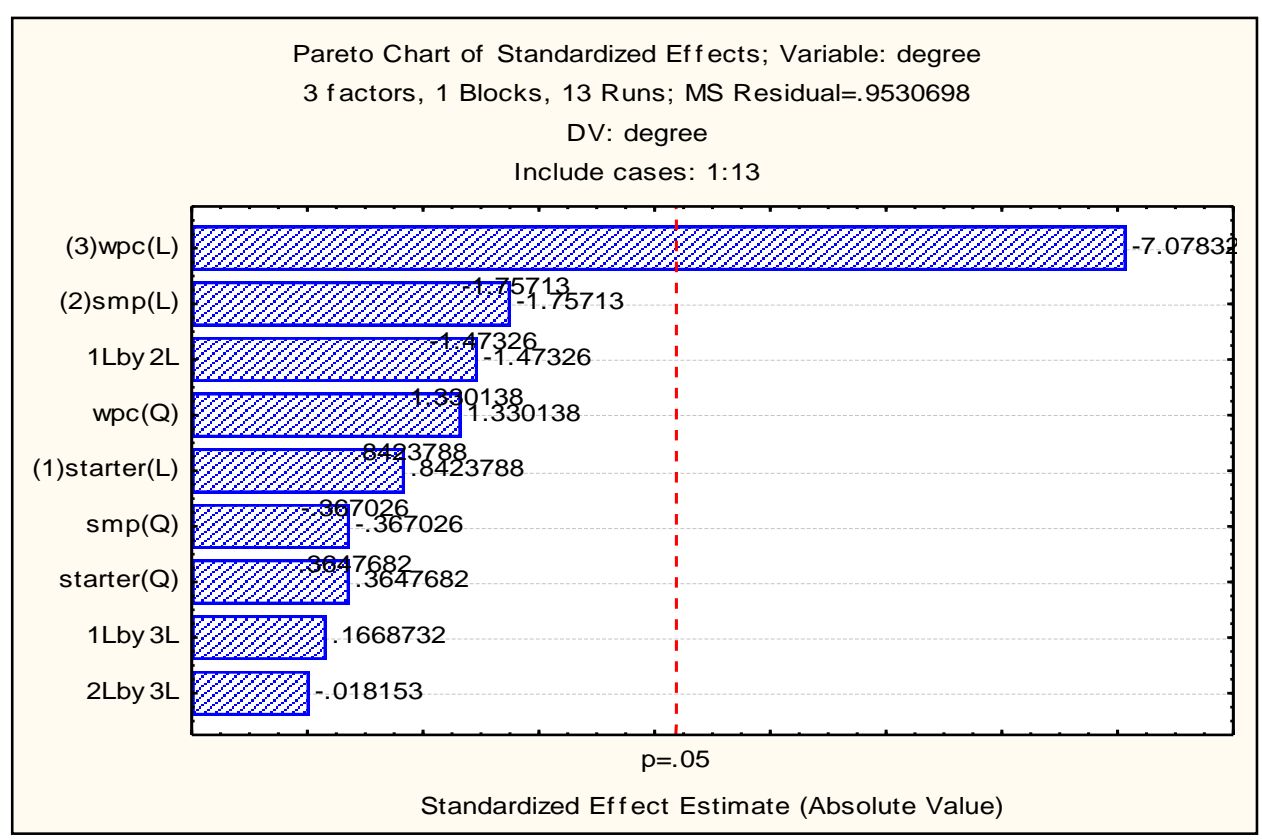



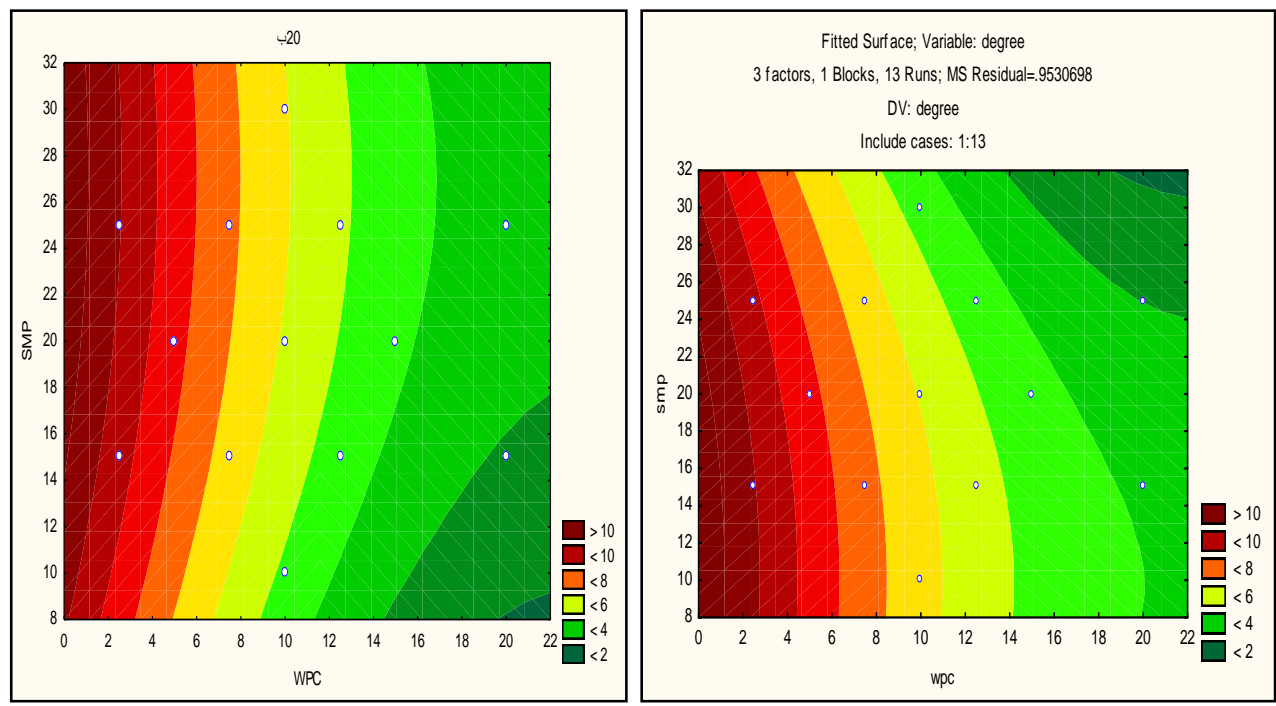

\section{DISCUSSION}

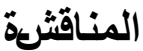

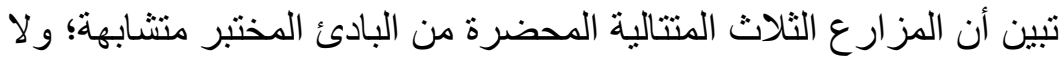

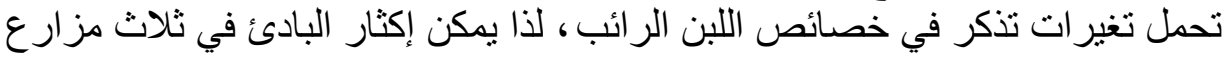

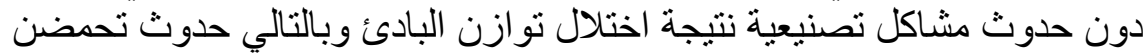

و هذا بتفق مع معايير إكثار البادئات واستعمالاتها الصناعية.

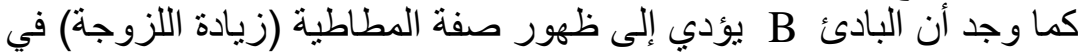
اللبن الرائب المنتج وذاللك يرجع إلى إنتاج عديد السكريد الخارجي عن طريق جر اثيم

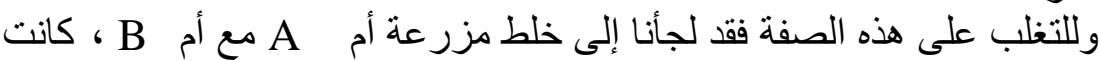
البوفيدوباكتر. أفضل نسبة هي B:A)2:8)، حيث أعطت لبن يمتاز بخو اص حسية جيدة دون ظهور صفة المطاطية

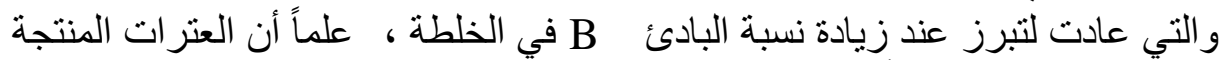

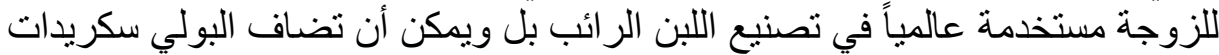

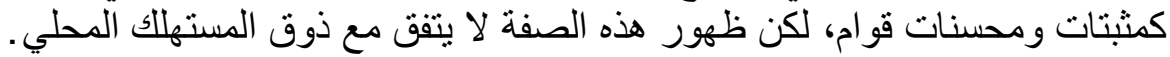




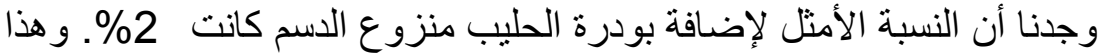

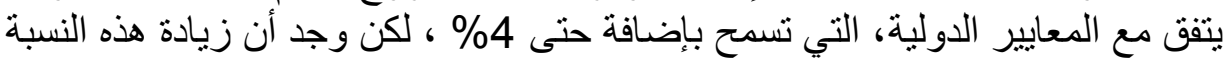

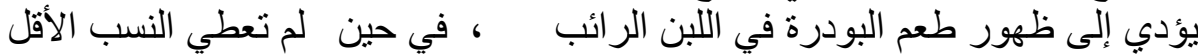

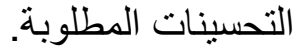

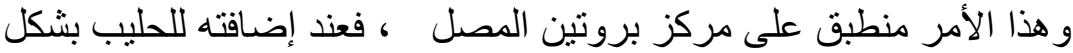

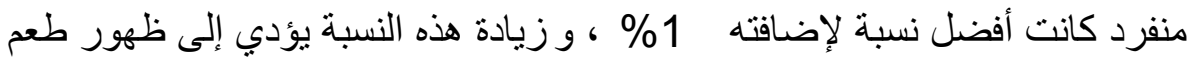

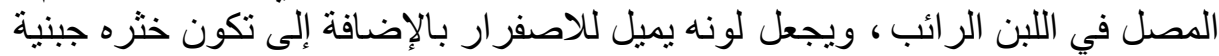

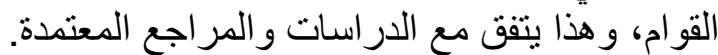

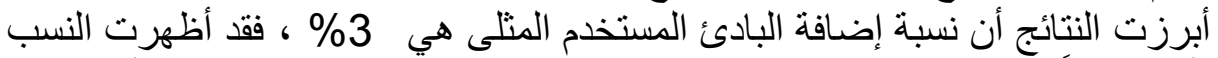

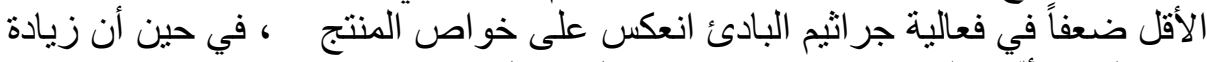

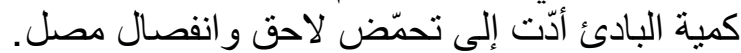

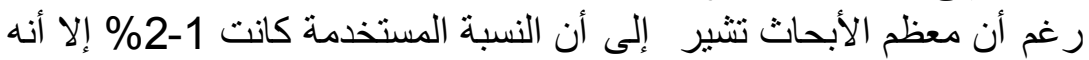

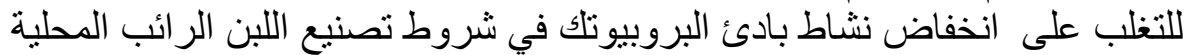

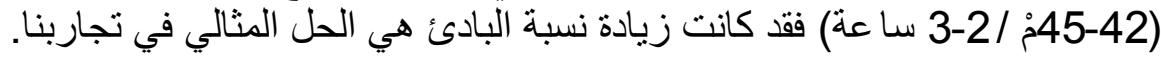

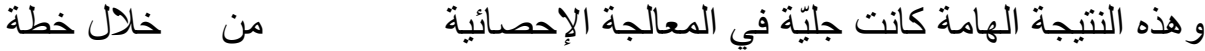

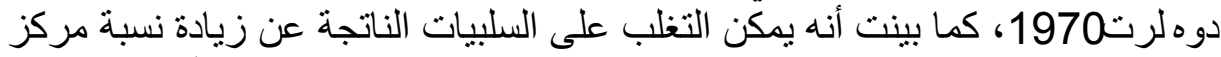

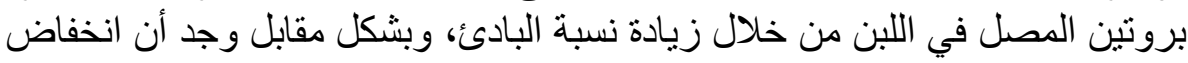

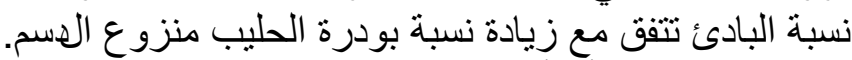

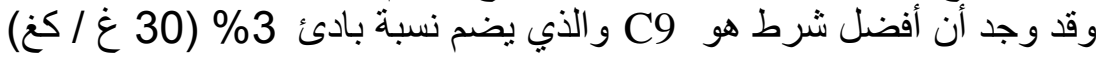

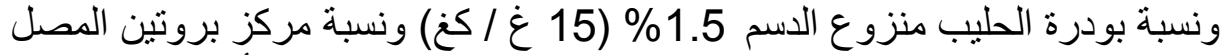

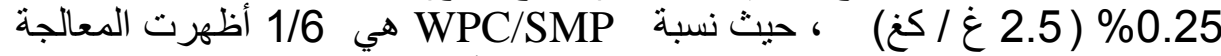

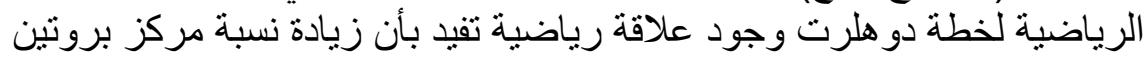
المصل تؤدي لانخفاض النو عية الحسية للبن الر ائب الناتج.

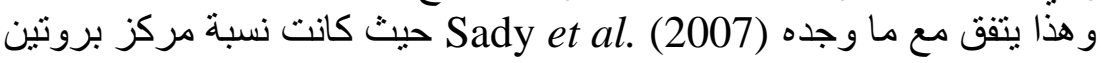
المصل أقل من نسبة بودرة الحليب ، و وقد يعود ذللك للتركيز الاصطفائي لمركز بروتئ مركين

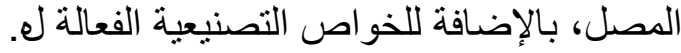
يستتتج من هذا البحث:

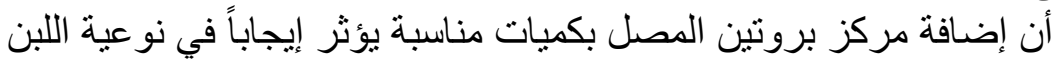

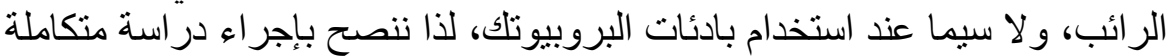

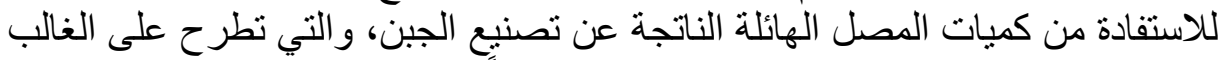

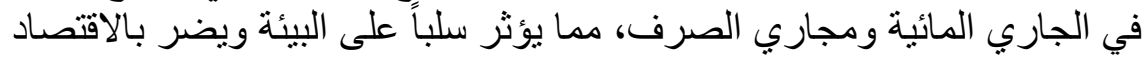
الوطني.

\section{REFERENCES}

Ackley, S.; Barrett-Conner, E. and Suarez, L. (1983): Dairy products, calcium, and blood pressure. Am. J. Clin Nutr, 38: 457-461. 
Akin, N. and Rice, P. (1994): Main yogurt and related products in Turkey. Cult. Dairy Prod. J. 29: 23, 25-26: 28-29.

Aoe, S.; Toba, Y. and Yamamura, J. (2001): Controlled trial of the effects of milk basic protein (MBP) supplementation on bone metabolism in healthy adult women. Biosci Biotechnol Biochem, 65: 913-918.

Beucler, J.; Drake, M. and Foegeding, E.A. (2004): Design of a thirst quenching beverage from whey permeate. Department of Food Science, North Carolina State University, Box 7624, Raleigh, $\mathrm{NC}, 27695$.

Bhatia, S.J.; Kochar, N.; Abraham, P.; Nair, N.G. and Mehta, A.P. (1989): Lactobacillus acidophilus inhibits growth of Campylobacter pylori in vitro. JClinMicrobiol.; 27(10): 23282330.

Bos, C.; Gaudichon, C. and Tome, D. (2000): Nutritional and physiological criteria in the assessment of milk protein quality for humans. J. Am. Coll Nutr, 19:191S-205S.

Buck, L.M. and Gilliland, S.E. (1994): Comparisons of freshly isolated strains of Lactobacillus acidophilus of human intestinal origin for ability to assimilate cholesterol during growth. J. Dairy Sci; 77(10): 2925-33

Burke, D.G.; Chilibeck, P.D. and Davidson, K.S. (2001): The effect of whey protein supplementation with and without creatine monohydrate combined with resistance training on lean tissue mass and muscle strength. Int. J. Sport Nutr Exerc Metab, 11: 349-364.

Casper, J.L.; Wendorff, W.L. and Thomas, D.L. (1999): Functional properties of whey proteins concentrates from caprine and ovine specialty cheese wheys. Journal of DairyScience, Vol. 82: 265-271.

Chandan, R. (1997): Dairy-Based Ingredients. Eagan Press Handbook Series. St. Paul, MN.

Cheng, L.J.; Augustin, M.A. and Clarke, P.T. (2000): Yogurts from skim milk whey protein concentrate blends. Australian Journal of Dairy Technology 55:110

Dave, R.I. and Shah, N.P. (1996): Evaluation of media for selective enumeration of Streptococcus thermophilus, Lactobacillus delbrueckii ssp. bulgaricus, Lactobacillus acidophilus, and bifidobacteria. J. of Dairy Science, 79: 1529-1536. 
Di Mario, F.; Aragona, G. and Bo, N.D. (2003): Use of lactoferrin for Helicobacter pylori eradication. Preliminary results. J. Clin Gastroenterol; 36: 396-398.

Di Mario, F.; Aragona, G. and Dal Bo, N. (2003): Use of bovine lactoferrin for Helicobacter pylori eradication. Dig Liver Dis; 35: 706-710.

Early, E.M.; Hardy, H.; Forde, T. and Kane, M. (2001): Bactericidal effect of a whey protein concentrate with anti-Helicobacter pylori activity. J. Appl. Microbiol; 90: 741-748.

FDA. (1996c): Yogurt. 21 CFR 131. 200, Code of Federal Regulations. U.S. Dept. of Health and Human Services, Washington, DC.

Francis, F.J. and Wiley, (2000): "Whey: Composition, Properties, Processing and Uses". Wiley Encyclopedia of Food Science and Technology. 2nd Edition. New York. p.2652-2661.

Gilliland, S.E.; Nelson, C.R. and Maxwell, C.V. (1985): Assimilation off cholesterol by Lactobacillus acidohpilus. Appl. Environ. Microbiol. 49: 377-381.

Graeff, F.G.; Guimaraes, F.S.; De Andrade, T.G. and Deakin, J.F. (1996): Role of 5-HT in stress, anxiety, and depression. Pharmacol Biochem Behav; 54: 129-141.

Guarner, F. and Schaafsma, G.J. (1998): Probiotics. Int. J. Food Microbiol, 39: 237-238.

Huffman, L.M. (1996): Processing whey protein for use as a food ingredient. Food Technology. 50: 49-52.

Hugunin, A. (1999): Whey products in yogurt and fermented dairy products. U.S. Dairy Export Council, 1-8.

Huis in't Veld, J.H.; Havenaar, R. and Marteau, P. (1994): Establishing a scientific basis for probiotic R\&D. Trends Biotechnol, 12(1): 6-8.

Kim, H.S. and Gilliland, S.E. (1983): Lactobacillus acidophilus as a dietary adjunct for milk to aid lactose digestion in humans. J. Dairy Sci. 66: 959-699.

Lands, L.C.; Grey, V.L. and Smountas, A.A. (1999): Effect of supplementation with a cysteine donor on muscular performance. J. Appl. Physiol, 87: 1381-1385.

Lilley, D.M. and Stillwell, R.H. (1965): Probiotics: growth promoting factors produced by microorganisms. Science; 147: 747-748.

MacKay, D. and Miller, A.L. (2003): Nutritional support for wound healing. Altern Med Rev; 8: 359-377. 
Mareschi, J.P. and Cueff, A. (1989): Essential characteristics of yogurt and its regulation around the world, p. 11-28. In Chandan, R.C. (ed.), Yogurt: Nutritional and Health Properties. National.

Markus, C.R.; Olivier, B. and De Haan, E.H. (2002): Whey protein rich in alpha-lactalbumin increases the ratio of plasma tryptophan to the sum of the other large neutral amino acids and improves cognitive performance in stress-vulnerable subjects. Am J. Clin. Nutr; 75: 1051-1056.

Markus, C.R.; Olivier, B. and Panhuysen, G.E. (2000): The bovine protein alpha-lactalbumin increases the plasma ratio of tryptophan to the other large neutral amino acids, and in vulnerable subjects raises brain serotonin activity, reduces cortisol concentration, and improves mood under stress. Am. J. Clin. Nutr; 71: 1536-1544.

Mccomas, J.R. and Gilliland, S.E. (2003): Growth of probiotic and traditional yogurt cultures in milk supplemented with whey protein hydrolysate. J. Food Sci., 68 (6): 2090-2095.

Midolo, P.D.; Lambert, J.R.; Hull, R.; Luo, F. and Grayson, M.L. (1995): In vitro inhibition of Helicobacter pylori by organic acids and lactic acid bacteria. J. Appl. Bacteriol. 79(4): 475-9.

Mistry, V.V. and Hassan, H.N. (1992): Manufacture of nonfat yogurt from a high milk protein powder. J. Dairy Sci. 75: 947-957.

Mustapha, A.; Jiang, T. and Savaiano, D.A. (1997): Improvement of Lactose Digestion by Humans Following Ingestion of Unfermented Acidophilus Milk: Influence of Bile Sensitivity, Lactose Transport, and Acid Tolerance of Lactobacillus acidophilus. J. Dairy Sci. 80 (8): 1537-1545.

Okada, S.; Tanaka, K. and Sato, T. (2002): Doseresponse trial of lactoferrin in patients with chronic hepatitis C. Jpn. J. Cancer Res; 93: 1063-1069.

Pasin, Dr.G. and Dr.S.L. Miller, Ph.D. (2000): U.S. Whey Products and Sports Nutrition. U.S. Dairy Export Council.

Rasic, J.L. and Kurmann, J.A. (1978): Yoghurt: Scientific Grounds, Technology, Manufacture and Preparation. Technical Dairy Publishing House, Berne, Switzerland.

Reiter, B. (1985): The biological significance of the nonimmunoglobulin protective proteins in milk: lysozome, lactoferrin, lactoperoxidase. Dev Dairy Chem; 3: 281-336.

Robinson, R.K. (2002): Dairy Microbiology Handbook, 3rd, ISBN 0471-38596-4, Wiley-Interscience, Inc. 
Russell, T.A. and Drake, M. (2004): Comparison of sensory properties of whey and soy protein concentrates and isolates. Department of Food Science, North Carolina State University, Box 7624, Raleigh, NC, 27695.

Sady, M.; Domagatal, J.; Gregal, T. and Najgebauer-Lejko, D. (2007): Quality Properties Of Non-Fat Yoghurt With Addition Of Whey Protein Concentrate. Biotechnology in Animal Husbandry 23 (5-6): 291-299.

Sanders, M.E. (1993): In Functional Food: Designer Food, Pharma foods and Neutraceutical, I. Goldberg,ed., Chapman and Hall, New York, p. 294-322.

Schorsch, C.; Wilkins, D.K.; Jones, M.G. and Norton, I.T. (2001): Gelation of casein-whey mixtures: effects of heating whey proteins alone or in the presence of casein micelles. J. Dairy Res. 68: 471-481.

Sekine, K.; Watanabe, E. and Nakamura, J. (1997): Inhibition of azoxymethane-initiated colon tumor by bovine lactoferrin administration in F344 rats. Jpn. J. Cancer Res; 88: 523-526.

Smithers, G.W.; Ballard, F.J.; Copeland, A.D.; De Silva, K.J.; Dionysius, D.A.; Francis, G.L.; Godard, C.; Griece, P.A.; McIntosh, G.H.; Mitchell, I.R.; Pearce, R.J. and Regester, G.O. (1996): New opportunities from the isolation and utilization of whey proteins. symposium: advances in dairy foods processing and engineering. J. Dairy Sci. 79: 1454-1459.

Smithers, G.W.; McIntosh, G.H. and Regester, G. (1998): Anti-cancer effects of dietary whey proteins. Proceedings of the Second International Whey Conference; 9804: 306-309.

Sodini, I.; Montella, J. and Phillip, S.T. (2005): Physical properties of yogurt fortified with various commercial whey protein concentrates. J. Sci. Food Agric. 85: 853-859.

Suzuki, T.; Yamauchi, K. and Kawase, K. (1989): Collaborative bacteriostatic activity of bovine lactoferrin with lysozyme against E. coli. Agric Biol Chem; 53: 1705-1706.

Takada, Y.; Kobayashi, N. and Kato, K. (1997): Effects of whey protein on calcium and bone metabolism in ovariectomized rats. J.Nutr Sci Vitaminol (Tokyo), 43: 199-210.

Takada, Y.; Kobayashi, N. and Matsuyama, H. (1999): Whey protein suppresses the osteoclast mediated bone resorption and osteoclast cell formation. Int. Dairy J., 7: 821-825. 
Takada, Y.; Aoe, S. and Kumegawa, M. (1996): Whey protein stimulated the proliferation and differentiation of osteoblastic MC3T3-E1 cells. Biochem Biophys Res Commun, 223:445-449.

Tamime, A.Y. and Robinson, R.K. (1999): Yoghurt: science and technology, $2^{\text {nd }}$ edn. Woodhead Publishing Limited, Cambridge.

Tamime, A.Y. and Deeth, H.C. (1980): Yogurt: technology and biochemistry. J. Food Prot., 43: 939-977.

Tamime, A.Y. and Robinson, R.K. (1985): Yoghurt: Science and Technology. Pergamon Press Ltd., Oxford, UK.

Tamime, A.Y.; Barclay, M.N.I.; Davies, G. and Barrantes, E. (1994): Production of low-calories yogurt using skim milk powder and fat-substitute.1. A review. Milchwissenschaft 49: 85-88.

Taranto, M.P.; Medici, M.; Perdigon, G.; Ruiz Holgado, A.P. and Valdez, G.F. (1998): Evidence for Hypocholesterolemic Effect of Lactobacillus reuteri in Hyper-cholesterolemic Mice. J. Dairy Sci. 81: 2336-2340.

Toba, Y.; Takada, Y. and Matsuoka, Y. (2001): Milk basic protein promotes bone formation and suppresses bone resorption in healthy adult men. Biosci Biotechnol Biochem, 65: 1353-1357.

Toba, Y.; Takada, Y. and Yamamura, J. et al. (2000): Milk basic protein: a novel protective function of milk against osteoporosis. Bone, 27: 403-408.

Tsuda, H.; Sekine, K. and Nakamura, J. (1998): Inhibition of azoxymethane initiated colon tumor and aberrant crypt foci development by bovine lactoferrin administration in F344 rats. Adv. Exp. Med. Biol. 443: 273-284.

Tsuda, H.; Sekine, K. and Ushida, Y. (2000): Milk and dairy products in cancer prevention:focus on bovine lactoferrin. Mutat Res; 462: 227-233.

Van Hooijdonk, A.C.; Kussendrager, K.D. and Steijns, J.M. (2000): In vivo antimicrobial and antiviral activity of components in bovine milk and colostrum involved in non-specific defence. Br. J. Nutr; 84: 127-134.

Vesovic, D.; Borjanovic, S.; Markovic, S. and Vidakovic, A. (2002): Strenuous exercise and action of antioxidant enzymes. Med. Lav., 93: 540-550.

Walker, D.K. and Gilliland, S.E. (1993): Relationships among bile tolerance, bile salt deconjugation and assimilation of cholesterol by Lactobacillus acidophilus. J. DairySci. 76: 956-961. 
Walzem, R.L.; Dillard, C.J. and German, J.B. (2002): Whey components: millennia of evolution create functionalities for mammalian nutrition: what we know and what we may be overlooking. Crit. Rev. Food Sci. Nutr; 42: 353-375.

Weinberg, E.D. (1996): The role of iron in cancer. Eur. J. Cancer Prev, 5: 19-36.

Yamamura, J.; Aoe, S. and Toba, Y. (2002): Milk basic protein (MBP) increases radial bone mineral density in healthy adult women. Biosci Biotechnol Biochem, 66: 702-704.

Yoo, Y.C.; Watanabe, S. and Watanabe, R. (1998): Bovine lactoferrin and lactoferricin inhibit tumor metastasis in mice. Adv. Exp. Med. Biol.; 443: 285-291.

Zemel, M.B. (2003): Mechanisms of dairy modulation of adiposity. J. Nutr., 133: 252-256.

Zimecki, M.; Wlaszczyk, A. and Wojciechowski, R. (2001): Lactoferrin regulates the immune responses in post-surgical patients. Arch. Immunol. Ther. Exp. (Warsz); 49: 325-333. 